\title{
Comparison between literature guidelines and developed projects regarding the land use criteria for the selection of the best management practices for stormwater
}

\author{
A. Romnée \\ Architecture et Climat, Université Catholique de Louvain, Belgium
}

\begin{abstract}
Major conventional and traditional public sanitation networks are out of date and have proven their limits to sustainably manage stormwater. Decentralized approach to stormwater management, whereby best management practices (BMP) are dispersed throughout the site project, has gained popularity in recent years. Stormwater BMPs provide an actual, alternative and more sustainable approach than the conventional practice of routing runoff through pipe systems. The selection of the appropriate stormwater BMP to a site project requires experiences and a fine appreciation of many selection criteria. BMPs may be selected according to a wide range of criteria regarding the land use characteristics, the site characteristics, the catchment characteristics, the quantity and quality performance requirements and the amenity, environmental, community and participation requirements. This paper gives a BMP selection aid tool based on a literature review of many public space projects designed with stormwater BMPs. BMPs are classified according to the land use and their position in the stormwater management train. The classification of BMPs proposed in the tool, and based on actually built project, is then compared to the BMPs selection guidelines found in the literature. It appears that, related to land use criteria for the selection of the appropriate BMP, the implementation of BMPs in developed projects is poorly correlated to the guidelines of the literature.
\end{abstract}

Keywords: best management practices, land use criteria, literature guidelines, sustainable urban stormwater management. 


\section{Introduction}

Since a few decades, a new paradigm in urban stormwater management is translated into the integration of decentralized drainage management facilities trying to maintain the condition of drainage after development as closest as possible to the situation before development [1]. These measures are commonly referred as SUDs (sustainable drainage systems) [1], BMPs (best management practices) [2] or LID (low-impact development stormwater drainage systems) [3]. There are many BMPs that meet this new approach such as swale, bioretention garden, infiltration trench, green roof, stormwater trees, dry, wet and infiltration basins or permeable pavements. Many studies, guidelines and reports, such as [1, 4-9], focussed on the design and performance of BMPs.

Selecting the appropriate BMPs for a development requires a fine appreciation of many decisive criteria. The opportunities and constraints of the site and the project have to be identified at the early stage of the selection process. BMPs may be selected according to a wide range of criteria regarding the land use characteristics, the site characteristics, the catchment characteristics, the quantity and quality performance requirements and the amenity, environmental, community and participation requirements.

Many studies classify the BMPs according to their quantity and quality performances (pollutant removal) related to the hydrologic processes active in the BMPs (storage, infiltration, evaporation) [1, 5, 7, 9-13, 14]. Other studies focus on the site constraints and characteristics (hydrogeology, soil features, slope, groundwater features) for selecting the most appropriate BMP [1, 4, 7, 11, 14]. A few studies consider the amenity, environmental and community requirements as relevant for the selection of BMPs, such as the ease of maintenance, the affordability and the safety $[1,7,9,11,14]$. The catchments characteristics or watershed factors are highlighted by many studies as criteria of selection for a BMP $[1,7,9]$. Finally, land use characteristics, developed in many studies $[1,4$, $6,11-13,15-17]$, are important to take into consideration while selecting a BMP.

Although BMPs are always presented as individual elements, they are often used in combination, forming a stormwater 'management train'. The management train is composed by a BMP located at the source position, by a BMP located at the end position and by one or many BMPs located between the extreme positions. Some authors define the most adequate position of each BMP in the management train $[4,10,12,15,18]$.

This paper develops a BMP selection methodology based on a review of 288 developed projects located worldwide. The scope of the paper is to give an overview of which BMP is used to be implemented, in which specific public space and at which position in the management train. The land use is the only criterion activated in the analysis because this criterion is the first to be considered by architects, urban planners and local authorities.

Firstly, a projects and BMPs database is created revealing the BMPs used to be integrated in many public space projects. Secondly, based on the database, the paper analyses the correlation between the stormwater BMPs and their implementation in developed projects according to their implementation in public 
spaces and according to their position in the management train. Finally, the paper compares the results of the analysis to a literature review of decision guidelines concerning the determination of which BMPs are best suited to the proposed land use. Comparisons show that the implementation of BMPs in developed projects is poorly correlated to the prescriptions of the literature.

\section{Method}

Our purpose is to study the integration of stormwater BMPs into public space projects. The author concentrates his study on eleven stormwater BMPs (stormwater trees, infiltration basin, wet basin, dry basin bioretention garden, swale, infiltration well, porous pavement, infiltration trench, storage roofs and green roofs) defined by Bruxelles Environnement [19, 20] and on five typologies of public spaces (roads, parking lots, residential areas, open spaces such as parks, sport areas, etc. and squares).

\subsection{Projects and BMPs database}

The author collects data from 288 projects worldwide from many studies, reports and existing database [7, 14, 21-31]. The International Stormwater BMP Database [24] furnishes the majority of the projects inventoried (183/288). Projects were selected according to their data concerning the BMPs and the public spaces typologies chosen for this study.

Data the author has collected concern the site of the project, the description of the BMPs management train and the costs of the drainage system (out of the scope for this paper). The information concerning the site are the name of the project, the spatial typology (among roads, parking lots, squares, open spaces or residential areas), the fact that the project is a new one or a retrofit one, the urban areas (urban/high density, sub-urban/low density or rural/sparse), the area of the watershed and the area of the BMPs. The information concerning the BMPs management train make references to the type, the volume of storage and the area for the BMP considered as a source, as a conveyance or as the end position in the management train. For the BMP located at the end position, the number of inflow points is mentioned, the distinction between the fact that the BMP is designed to bypass or to overflow is mentioned and the presence of an upstream treatment is mentioned.

\subsection{Literature summary of BMPs selection based on land use criteria}

Many studies or reports and urban planners and architects consider the land use as a primary criterion in order to select an adequate BMP for stormwater management. Land use reviewed in the literature concern the residential lots, the roads and highways, the rural areas, the high density or ultra-urban or commercial areas, the sidewalks, the parking lots and the open space areas (parks, sport and recreation areas, etc.).

Table 1 reports the most frequently appeared classification of many stormwater BMPs and the associated land use from many references $[1,4,6,8,9,13,16,17]$. 
Four levels of compatibility between the BMP and the land use are used: high, i.e. the BMP is a good option for the land use; middle, i.e. the BMP is suitable for the land use; low, i.e. the BMP is suitable under certain conditions; (empty), i.e. the BMP is not suitable or not mentioned as suitable in the literature.

Table 1: Literature summary of compatibility between BMPs and land use.

\begin{tabular}{|c|c|c|c|c|c|c|}
\hline & 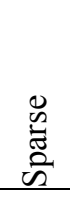 & 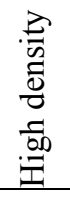 & 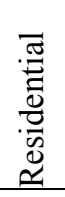 & $\begin{array}{l}\tilde{E} \\
\stackrel{\tilde{Z}}{0} \\
\underline{\underline{1}}\end{array}$ & 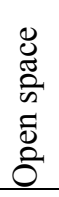 & 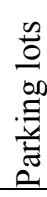 \\
\hline Stormwater trees & & & & + & + & \\
\hline Infiltration basin & $+/-$ & - & $+/-$ & $+/-$ & + & \\
\hline Wet basin & + & - & + & $+/-$ & + & \\
\hline Dry basin & & - & + & - & & \\
\hline Bioretention garden & $+/-$ & $+/-$ & $+/-$ & $+/-$ & + & + \\
\hline Swale & + & $+/-$ & $+/-$ & $+/-$ & + & + \\
\hline Infiltration well & $+/-$ & $+/-$ & $+/-$ & - & & \\
\hline Porous pavement & & $+/-$ & + & + & + & + \\
\hline Infiltration trench & $+/-$ & $+/-$ & $+/-$ & $+/-$ & + & + \\
\hline Storing roof & & & + & & & \\
\hline Green roof & & $+/-$ & + & & & \\
\hline
\end{tabular}

BMPs are also classified according to their most suited location in the management train (source, conveyance or end). The source position is the most upstream position in the management train, closest as where the rain falls. The end position is the most downstream position in the management train, before the outlet. A BMP located at the conveyance position aims to convey runoff from upstream to downstream.

Table 2 reports from many references $[1,4,12,15,18,32]$ the classification of some stormwater BMPs according to their location in the drainage management train, i.e. source, conveyance or end position.

\section{Results}

\subsection{Analysis of the database}

Two statistical analysis, based on the frequency of occurrence and its attached standard deviation $\sigma$, of the database are produced. 
Table 2: Literature summary of suitable positions of BMPs in the drainage train.

\begin{tabular}{|l|c|c|c|}
\hline & Source & Conveyance & End \\
\hline Stormwater trees & + & & \\
\hline Infiltration basin & & & $+/-$ \\
\hline Wet basin & $+/-$ & & + \\
\hline Dry basin & $+/-$ & & + \\
\hline Bioretention garden & + & & \\
\hline Swale & & + & $+/-$ \\
\hline Infiltration well & + & & $+/-$ \\
\hline Porous pavement & + & $+/-$ & \\
\hline Infiltration trench & $+/-$ & $+/-$ & \\
\hline Storing roof & + & & \\
\hline $\begin{array}{l}\text { Green roof } \\
+ \\
+=\text { suitable; } \\
+ \text { - = more or less suitable; } \\
\text { (empty) = not suitable. }\end{array}$ & + & & \\
\hline
\end{tabular}

Firstly, for each public space typology, i.e. roads, parking lots, residential, open spaces and squares, BMPs are classified according to the frequency they are used in the projects database. Four levels of classification are employed to characterize the relevance of the use of the BMPs for the specific public space typology. The levels reveal the compatibility of the BMP with the land use and are established according to the standard deviation $\sigma$ of the frequency of use of the BMP, as follow: Level 1 reveals a high compatibility, i.e. the BMP is the most frequently used; Level 2 reveals a middle compatibility, i.e. the frequency of use of the BMP is higher than the standard deviation $\sigma$ and lower than the frequency of the most frequent BMP; Level 3 reveals a low compatibility, i.e. the frequency of use of the BMP is lower than the standard deviation $\sigma$ and higher than zero; Level 4 reveals that the BMP is not compatible, i.e. the BMP was never met in the database.

The analysis of the database shows that swales represent nearly one quarter of the BMPs used in roads public space projects. Porous pavement is the most frequently used BMP for parking lot projects. In residential public space projects, wet basins are the most frequently used BMP. One third of the BMPs used in open space projects are wet basins. Dry basins and wet basins are equally used for squares. Table 3 summarizes the results of the level of compatibility analysis of BMPs with specific public spaces, i.e. the land use, within developed projects.

The second analysis of the database concerns the frequently allocated position of the BMPs in the drainage management train. The level of compatibility, based on the standard deviation $\sigma$ of the frequency of use, is employed to classify the BMPs allocated to the source position, or the conveyance position or the end position in the management train.

Results show that nearly one half of the BMPs used as the most upstream position in the management train are porous pavements. Swales and porous pavements are widely used for conveyance in the management train. Wet basins are the most frequently used BMPs for the end control position. 
Table 3: Compatibility between BMPs and land use (based on developed projects).

\begin{tabular}{|l|c|c|c|c|c|}
\hline & Road & Parking & Residential & Open space & Square \\
\hline Stormwater trees & - & & & & \\
\hline Infiltration basin & - & - & - & - & \\
\hline Wet basin & $+/-$ & $+/-$ & + & + & + \\
\hline Dry basin & $+/-$ & - & - & $+/-$ & + \\
\hline Bioretention garden & $+/-$ & $+/-$ & - & - & $+/-$ \\
\hline Swale & + & $+/-$ & $+/-$ & $+/-$ & $+/-$ \\
\hline Infiltration well & - & - & & & - \\
\hline Porous pavement & $+/-$ & + & $+/-$ & & $+/-$ \\
\hline Infiltration trench & $+/-$ & - & - & - & - \\
\hline Storing roof & & & - & & - \\
\hline Green roof & & & $+/-$ & - & \\
\hline
\end{tabular}

$+=$ high compatibility (most frequently used);

$+/-=$ middle compatibility (higher than the standard deviation);

$-=$ low compatibility (lower than the standard deviation, higher than zero);

$($ empty $)=$ not compatible or not mentioned (never used).

Table 4 summarizes the results of the classification of many stormwater BMPs according to their location in the management train.

Table 4: Adequate position of BMPs in the drainage management train (based on developed projects).

\begin{tabular}{|l|c|c|c|}
\hline & Source & Conveyance & End \\
\hline Stormwater trees & - & & \\
\hline Infiltration basin & & & - \\
\hline Wet basin & & & + \\
\hline Dry basin & & & $+/-$ \\
\hline Bioretention garden & $+/-$ & - & $+/-$ \\
\hline Swale & - & + & $+/-$ \\
\hline Infiltration well & & - & - \\
\hline Porous pavement & + & $+/-$ & - \\
\hline Infiltration trench & - & - & - \\
\hline Storing roof & - & & \\
\hline Green roof & $+/-$ & & - \\
\hline
\end{tabular}

$+=$ high adequacy (most frequently used);

$+/-=$ middle adequacy (higher than the standard deviation);

$-=$ low adequacy (lower than the standard deviation, higher than zero);

$($ empty) $=$ not adequate (never used). 


\subsection{Comparison between guidelines and developed projects}

Two comparisons are proceeded, in order to verify if the BMPs guidelines and selection tools encountered in the literature are useful when designing public space projects with BMP.

In both comparisons, symbols used to notify the compatibility of the BMP ' + ', '+/-', '-' and '(empty)' in Tables 1 to 4 are translated into numeric value, as follow: $($ empty $)=1 ;-=2 ;+/-=3$ and $+=4$. By this way, we may calculate the relative bias (RB) between the data of the guidelines and the data of the developed projects; i.e. between Tables 1 and 2 and Tables 3 and 4. RB is expressed as a percentage representing the difference of evaluation between an experimented variable $\mathrm{X}_{\exp }$ and a reference variable $\mathrm{X}_{\text {ref }}$.

$$
R B=\frac{X_{\text {exp }}-X_{\text {ref }}}{X_{\text {ref }}}
$$

In our comparisons, the experiment variable represents the results of the analysis of the database (Tables 3 and 4) and the reference variable represents the results of the summary of the literature review (Tables 1 and 2).

For example, if a BMP receives the symbol ' + ', i.e. the value 4 in the numeric system, for the compatibility with a particular land use in the literature review and receives the symbol '-' , i.e. the value 2 in the numeric system, according to the analysis of developed projects, $R B=\frac{2-4}{4}=-50 \%$. A negative relative bias means that the BMP is underused in the developed projects than it is advised in the guidelines. A positive relative bias means that the BMP is overused in the developed projects than it is advised in the guidelines. A null relative bias means that the BMP is equally used in the developed projects than it is advised in the BMP.

Based on the numerical values of the correlated symbols in Tables 1-4, the authors evaluates the coefficient of linear correlation $\mathrm{R}$ between the results of the analysis of the database and the guidelines of the literature review.

$$
R=\frac{\operatorname{cov}(X, Y)}{\sigma_{X} \sigma_{Y}}
$$

As expressed in eqn (2), the coefficient or linear correlation $\mathrm{R}$ is the covariance between two vectors $\mathrm{X}$ and $\mathrm{Y}$ divided by the multiplication of the standard deviation of both vectors. In both comparisons realized in this section, $\mathrm{X}$ represents the results of the analysis of the database (Tables 3-4) and Y represents the results of the literature review (Tables 1-2).

The first comparison is between Table 1 and Table 3 and concerns the implementation of BMPs according to the land use.

Figure 1 shows that regarding road projects, the implementation of infiltration wells, s and wet basins (and of course storing and green roofs) follows the recommendation of the guidelines $(\mathrm{RB}=0 \%)$. Stormwater trees, infiltration basins and porous pavements are less implemented in developed projects than recommended in guidelines $(\mathrm{RB}<0 \%)$. Dry basins and swales are more implemented than expected in guidelines $(\mathrm{RB}>0 \%)$. 


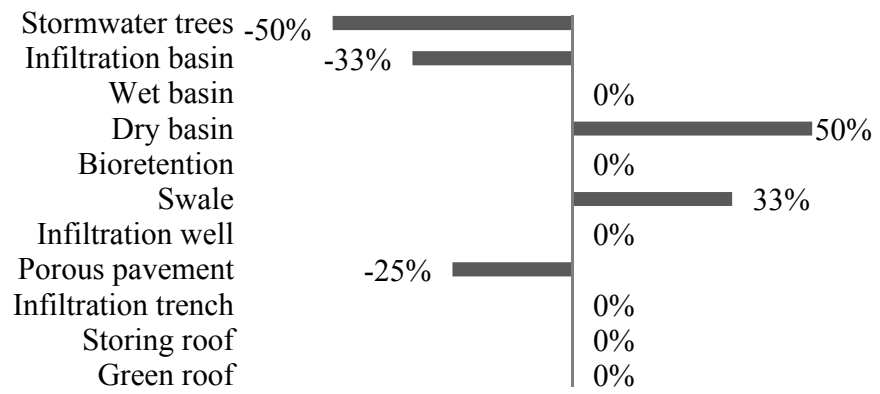

Figure 1: Relative bias of compatibility of BMPs with roads between guidelines and developed projects.

Figure 2 shows that regarding parking lot projects, the implementation of porous pavements and stormwater trees (and of course green and storing roofs) follows the recommendation of the guidelines $(\mathrm{RB}=0 \%)$. Bioretention gardens, swales and infiltration trenches are less implemented in developed projects than recommended in guidelines $(\mathrm{RB}<0 \%)$. Dry, wet and infiltration basins and infiltration wells are more implemented than expected in guidelines $(\mathrm{RB}>0 \%)$.

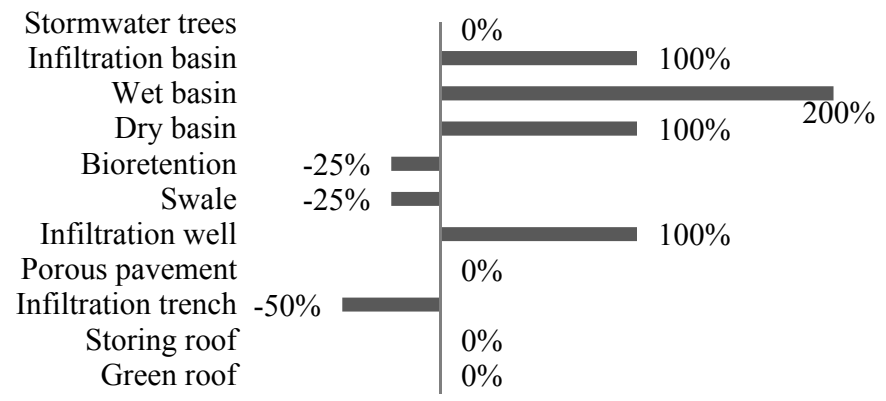

Figure 2: Relative bias of compatibility of BMPs with parking lots between guidelines and developed projects.

Figure 3 shows that regarding residential projects, the implementation of swales, wet basins and stormwater trees follows the recommendation of the guidelines $(\mathrm{RB}=0 \%)$. All other BMPs are less implemented in developed projects than recommended in guidelines $(\mathrm{RB}<0 \%)$.

Figure 4 shows that regarding open space projects, the implementation of storing roofs, infiltration wells and wet basins follows the recommendation of the guidelines $(\mathrm{RB}=0 \%)$. Infiltration trenches, porous pavements, swales, bioretention gardens, infiltration basins and stormwater trees are less implemented in developed projects than recommended in guidelines $(\mathrm{RB}<0 \%)$. Green roofs and dry basins are more implemented than expected in guidelines ( $\mathrm{RB}>0 \%$ ).

Table 5 gives the coefficient of linear correlation $\mathrm{R}$ between the developed projects and the literature regarding the land use criteria. 
Stormwater trees

Infiltration basin

Wet basin

Dry basin

Bioretention

Swale

Infiltration well

Porous pavement

Infiltration trench

Storing roof

Green roof

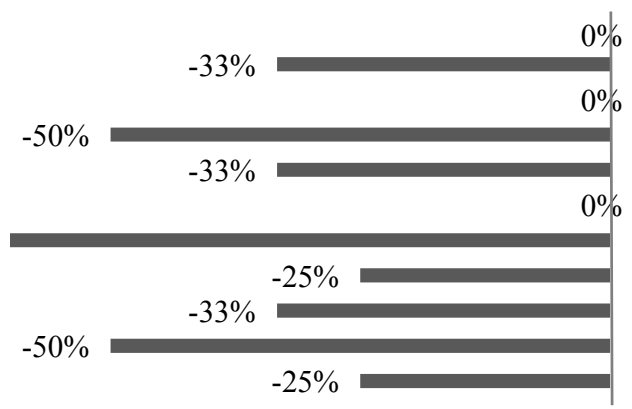

Figure 3: Relative bias of compatibility of BMPs with residential projects between guidelines and developed projects.

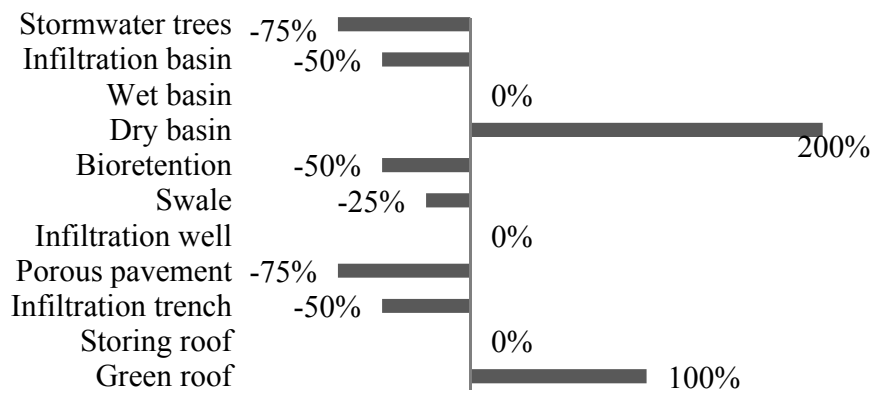

Figure 4: Relative bias of compatibility of BMPs with open space projects between guidelines and developed projects.

Table 5: Correlation between the implementation of BMPs in developed projects and the selection guidelines of BMPs, based on land use criteria.

\begin{tabular}{|l|c|}
\hline Land use & $\mathrm{R}$ \\
\hline Roads & 0.55 \\
\hline Parking lots & 0.6 \\
\hline Residential areas & 0.58 \\
\hline Open spaces & 0.18 \\
\hline
\end{tabular}

Table 5 reveals that, concerning open space land use, the implementation of BMPs in developed projects is positively but very poorly correlated $(\mathrm{R}<0.2)$ to the recommendations of the literature guidelines. Otherwise, concerning roads, parking lots and residential areas land use, the implementation of BMPs in developed projects is positively and relatively well correlated ( $\mathrm{R} \geq 0.5$ ) to the recommendations of the literature guidelines. 
The second comparison, between Table 2 and Table 4, concerns the adequate location of the BMPs in the management train.

Figure 5 shows that regarding the source control position in the management train, the implementation of infiltration basins and porous pavements follows the recommendation of the guidelines $(\mathrm{RB}=0 \%)$. Stormwater trees, wet and dry basins, bioretention gardens, infiltration wells, infiltration trenches, storing and green roofs are less implemented in developed projects than recommended in guidelines $(\mathrm{RB}<0 \%)$. Swales are more implemented than expected in guidelines $(\mathrm{RB}>0 \%)$.

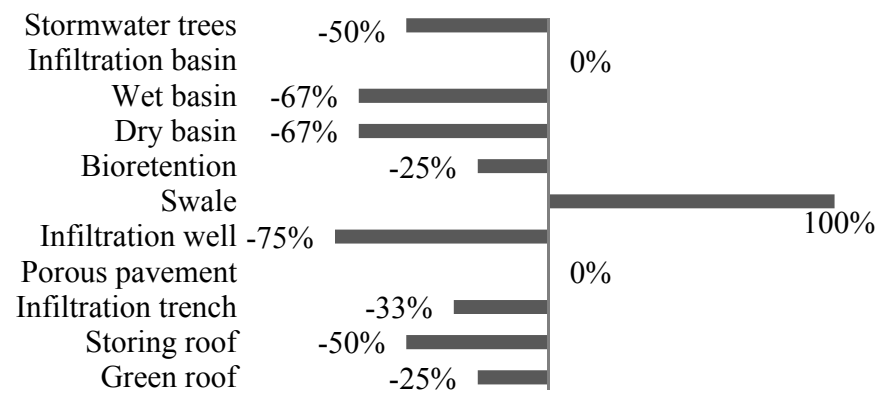

Figure 5: Relative bias between guidelines and developed projects regarding the source control position of BMPs in the management train.

Figure 6 shows that regarding the conveyance control position in the management train, the implementation of all BMPs follows the recommendation of the guidelines $(\mathrm{RB}=0 \%)$, excepted for the bioretention gardens, the infiltration wells and the infiltration trenches. Infiltration trenches are less implemented in developed projects than recommended in guidelines $(\mathrm{RB}<0 \%)$. Bioretention gardens and infiltration wells are more implemented than expected in guidelines $(\mathrm{RB}>0 \%)$.

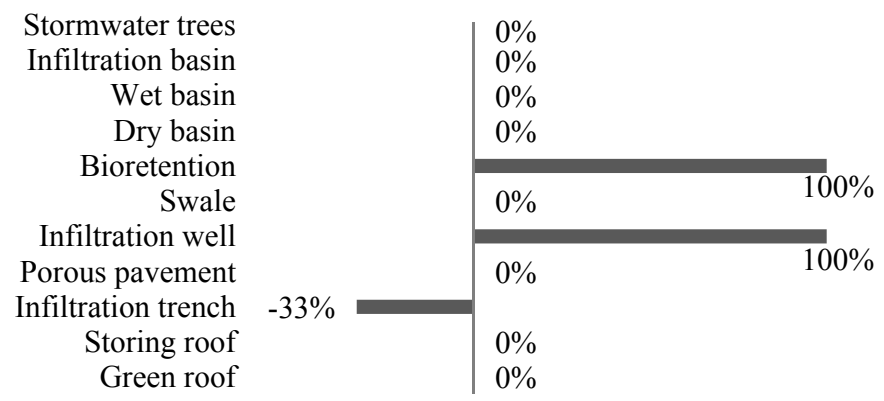

Figure 6: Relative bias between guidelines and developed projects regarding the conveyance control position of BMPs in the management train. 
Figure 7 shows that regarding the end control position in the management train, the implementation of stormwater trees, wet basins, swales and storing roofs follows the recommendation of the guidelines $(\mathrm{RB}=0 \%)$. Infiltration and dry basins and infiltration wells are less implemented in developed projects than recommended in guidelines $(\mathrm{RB}<0 \%)$. Bioretention gardens, porous pavements, infiltration trenches and green roofs are more implemented than expected in guidelines $(\mathrm{RB}>0 \%)$.

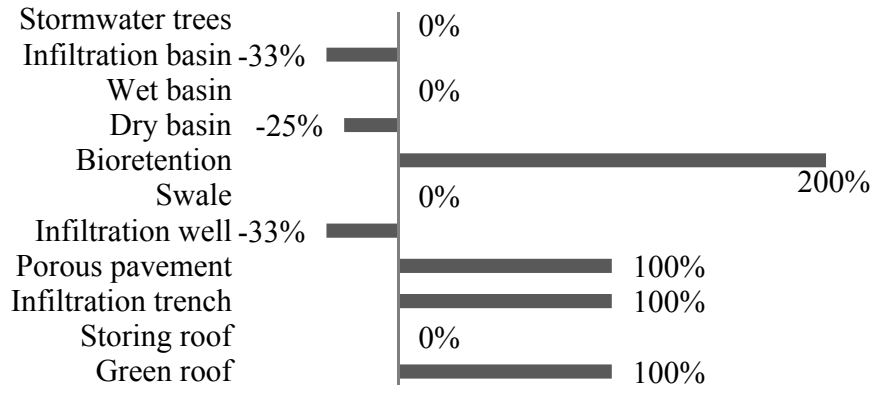

Figure 7: Relative bias between guidelines and developed projects regarding the end control position of BMPs in the management train.

The coefficient of linear correlation is calculated for each location in the management train, considering the level of compatibility of all BMPs in the evaluation. Table 6 gives the coefficient of linear correlation $\mathrm{R}$ between the developed projects and the literature regarding the position criterion.

Table 6: Correlation between the drainage location of BMPs in developed projects and the selection guidelines of BMPs, based on land use criteria.

\begin{tabular}{|l|c|}
\hline Land use & $\mathrm{R}$ \\
\hline Source & 0.39 \\
\hline Conveyance & 0.80 \\
\hline End & 0.60 \\
\hline
\end{tabular}

Table 6 reveals that, concerning the source position, the implementation of BMPs in developed projects is positively but poorly correlated $(\mathrm{R}<0.5)$ to the recommendations of the guidelines. Concerning the end position, the implementation of BMPs in developed projects is positively and relatively strongly correlated $(R \geq 0.5)$ to the recommendations of the guidelines. Finally, concerning the conveyance position the implementation of BMPs in developed projects is positively and strongly correlated $(\mathrm{R} \geq 0.8)$ to the recommendations of the guidelines. 


\section{Discussion}

The selection of the most adequate stormwater best management practice to a specific public space project requires to take into consideration lots of criteria. Among these criteria, the land use criterion is directly related to the design process.

Many publications (articles, reports or manuals) give recommendations and guidelines for the selection of a BMP regarding the land use criteria and the projected public space. The paper gives a summary of the literature review for the selection of the most appropriate BMP for roads, parking lots, residential areas, open spaces and squares projects. Often, a BMP is not implemented alone but it is incorporated into a stormwater management train. The position of the BMP within the management train depends on its quantity and quality control characteristics. The paper gives a summary of the literature review for the most suitable position of a BMP in a stormwater management train.

The analysis of a project and BMPs database, based on 288 worldwide projects of public spaces implementing BMPs, reveals that swales are the most frequently used BMPs for road projects; porous pavement is the most frequently used BMP for parking lots and wet basin is the most frequently used BMP for residential areas, open spaces and square projects. Moreover, the analysis of the database shows that wet, dry or infiltration basins are widely used in developed projects as end control position facilities in the management train. Swales and porous pavements are mainly implemented as conveyance BMPs. Porous pavements, bioretention gardens and green roofs are mostly located as source control BMPs in the management train.

It appears that the implementation of BMPs in developed projects is poorly correlated to the recommendations of the literature guidelines; except for the correlation for the conveyance BMPs for which the selection of the BMPs in developed projects are highly correlated to the literature review. This result means that, based on land use criteria, implementing BMPs in actual developed projects differs from the selection process expressed in the literature.

This difference between the literature and the actual projects may come from the fact that this paper focuses only on the land use criteria. Still keeping the method proposed in this paper, a further research should reveal the correlation between the guidelines and the developed projects considering the whole spectra of criteria (land use characteristics, catchment characteristics, site characteristics, quantity and quality performance requirements and amenity, environmental, community and participation requirements).

\section{References}

[1] CIRIA C687, The SUDS Manual, CIRIA, London, 2007.

[2] Field, R., Selvakumar, A., Sullivan, D., Muthukrishnam, S. \& Madge, B., The Use of Best Management Practices (BMPs) in Urban Watersheds, National Risk Management Research Laboratory, Office of Research and 
Development, United States Environmental Protection Agency (USEPA), EPA-600-R-04-184, Cincinnati, OH., 2004.

[3] Elliott, A.H. \& Trowsdale, S.A., A review of models for low impact urban stormwater drainage, Environmental Modelling \& Software, 22, pp. 394405, 2007.

[4] Ministère du Développement durable, de l'Environnement, et des Parcs, Ministère des Affaires municipales, des Régions et de l'Occupation du territoire, MDDEP, MAMROT, Guide de gestion des eaux pluviales Stratégies d'aménagement, principes de conception et pratiques de gestion optimales pour les réseaux de drainage en milieu urbain, 2012.

[5] Urban Drainage and Flood Control District (UDFCD), Urban Storm Drainage Criteria Manual - Volume 3, Best Management Practices, Urban Drainage and Flood Control District, Denver, Colorado, p. 589, 2010.

[6] Low Impact Development, Community stormwater management guidelines for Arthur Capper - Carrollsburg Dwellings, http://www.lowimpactdevel opment.org/lid\%20articles/AC_REPORT_final_5_15.pdf (20/11/2014).

[7] Minnesota Stormwater Steering Committee, Minnesota Stormwater Manual. Minnesota Pollution Control Agency, St Paul, Minnesota, p. 883, 2008.

[8] Stormwater Manager's Resource Center (SMRC), http://www.stormwater center.net/Manual_Builder/Selection_Matrices/matrix_1.htm (20/11/2014).

[9] New York State, Stormwater Management Design Manual, Prepared by Center for Watershed Protection for New York State Department of Environmental Conservation, Albany, NY, p. 642, 2010.

[10] Rivard, G., Gestion des eaux pluviales en milieu urbain: concepts et applications. Sainte-Dorothée, Québec: Alias communication design, p. 329, 1998.

[11] North Carolina Division of Water Quality, Stormwater Best Management Practices Manual, North Carolina Department of Environment and Natural Resources, p. 332, 2007.

[12] Alberta Ministry of the Environment (MEA), Stormwater management guidelines for the Province of Alberta, Municipal Program Development Branch Environmental Sciences Division Environmental Service, Alberta, p. $196,1999$.

[13] Lille Métropole Communauté Urbaine, Guide des eaux pluviales de Lille Métropole, CETE Nord, Lille, p. 77, 2012.

[14] Marti, M., Filipiak, D. \& Goddard, L., Decision Tree for Stormwater BMPs, Prepared by SRF Consulting Group, Inc. for Minnesota Department of Transportation Research Services Section, MN/RC - 2011RIC01, St Paul, MN, p. 58, 2011.

[15] Boucher, I., La gestion durable des eaux de pluie, Guide de bonnes pratiques sur la planification territoriale et le développement durable, Ministère des Affaires municipales, des Régions et de l'Occupation du territoire, coll. "Planification territoriale et développement durable", 2010, p. 118, (www.mamrot.gouv.qc.ca). 
[16] Rodriguez, M.I., Cuevas, M.M., Martinez, G. \& Moreno, B., Planning criteria for water sensitive urban design, In: Urban Water II, WIT Press: Southampton, Boston, 2014.

[17] Greater Vancouver Regional District (GVRD), Stormwater Source Controls Design Guidelines, Vancouver, Colombie-Britannique, Canada, 2012.

[18] Stahre, P. \& Geldof, G.D., New Approach to Sustainable Stormwater Planning, International Green Roof Institute (IGRI), Malmö, Sweden, 2003.

[19] Outil de gestion de l'eau à l'échelle du quartier, Info-fiche GEQ03: Modéliser un projet local, Bruxelles Environnement, 2014.

[20] Guide pratique pour la construction et la rénovation durables de petits bâtiments, Info-fiche OGE07: Les toitures stockantes, Bruxelles Environnement, 2010.

[21] Bruxelles Environnement (IBGE), Etude présentant des projets innovants en matière de gestion des eaux pluviales sur l'espace public et en voirie, Rapport d'étude menée dans le cadre de l'Alliance Emploi Environnement Eau (AEEE), Bruxelles, 2014.

[22] Islington Council, Promoting Sustainable Drainage Systems. Design guidance for Islington, Islington, p. 34.

[23] Shaver, E., Low Impact Design Versus Conventional Development: Literature Review of Developer-related Costs and Profit Margins, Prepared by Aqua Terra International Ltd. for Auckland Regional Council, Auckland Regional Council Technical Report 2009/045, 2009.

[24] United States Environmental Protection Agency (USEPA), International Stormwater BMP Database, Prepared with ASCE, USEPA, WERF, FHWA, APWA and EWRI, http://www.bmpdatabase.org (21/11/2014).

[25] Susdrain, SUSDRAIN Cases studies, http://www.susdrain.org/ $(27 / 10 / 2014)$.

[26] United States Environmental Protection Agency (USEPA), Reducing Stormwater Costs through Low Impact Development (LID) Strategies and Practices, Nonpoint Source Control Branch (4503T), Washington DC, 2007.

[27] The City of Portland Oregon, Cases studies, Environmental Services, Portland, https://www.portlandoregon.gov/bes/44463 (24/10/2014).

[28] Adopta, Fiches de cas, http://www.adopta.fr/site/_(27/10/2014).

[29] Pennsylvania Department of Environmental Protection (PADEP), Pennsylvania Stormwater Best Management Practices Manual, Bureau of Watershed Management, Pennsylvania, 2006, p. 642.

[30] Urban Green Blue Grids for sustainable and resilient cities, Example projects, http://www.urbangreenbluegrids.com/ (31/10/2014).

[31] Dreiseitl, H. \& Grau, D., New Waterscapes: planning, building and designing with water, Basel, Boston, Birkhaeuser, p. 176, 2005.

[32] Ontario Ministry of the Environment (MOE), Stormwater Management Planning and Design Manual, Ontario, p. 379, 2003. 